\title{
Evaluation of doxorubicin-loaded pH-sensitive polymeric micelle release from tumor blood vessels and anticancer efficacy using a dorsal skin-fold window chamber model
}

\author{
Zhe-hu JIN 1, 2, \#, Ming-ji JIN ${ }^{1, \#}$, Chang-gao JIANG², Xue-zhe YIN², Shuai-xing JIN², Xiu-quan QUAN², Zhong-gao GAO ${ }^{1,2, *}$ \\ ${ }^{1}$ State Key Laboratory of Bioactive Substances and Functions of Natural Medicines, Chinese Academy of Medical Sciences, Beijing \\ 100050, China; ${ }^{2}$ Yanbian University Hospital, Yanji 133000, China
}

\begin{abstract}
Aim: To evaluation the doxorubicin (DOX)-loaded pH-sensitive polymeric micelle release from tumor blood vessels into tumor interstitium using an animal vessel visibility model, the so-called dorsal skin-fold window chamber model.

Methods: DOX-loaded $\mathrm{pH}$-sensitive polyHis- $b$-PEG micelles and DOX-loaded $\mathrm{pH}$-insensitive PLLA- $b$-PEG micelles were prepared. The uptake of the micelles by MDA-MB-231 breast cancer cells in vitro and in vivo was examined using flow cytometry. The pharmacokinetic parameters of the micelles were determined in SD rats after intravenous injection of a DOX dose (6 mg/kg). The release of the micelles from tumor vasculature and the antitumor efficacy were evaluated in MDA-MB-231 breast cancer xenografted in nude mice using a dorsal skin-fold window chamber.

Results: The effective elimination half-life $t_{1 / 2}$ of the $\mathrm{pH}$-sensitive, $\mathrm{pH}$-insensitive polymeric micelles and DOX-PBS in rats were $11.3 \mathrm{~h}, 9.4 \mathrm{~h}$, and $2.1 \mathrm{~h}$, respectively. Intravital microscopy in MDA-MB-231 breast cancer xenografted in nude mice showed that the $\mathrm{pH}$-sensitive polymeric micelles rapidly extravasated from the tumor blood vessels, and DOX carried by the $\mathrm{pH}$-sensitive micelles was preferentially released at the tumor site as compared to the $\mathrm{pH}$-insensitive polymeric micelles. Furthermore, the $\mathrm{pH}$-sensitive polymeric micelles exhibited significant greater efficacy in inhibition of tumor growth in the nude mice.

Conclusion: When DOX is loaded into pH-sensitive polymeric micelles, the acidity in tumor interstitium causes the destabilization of the micelles and triggers drug release, resulting in high local concentrations within the tumor, thus more effectively inhibiting the tumor growth in vivo.
\end{abstract}

Keywords: anticancer drug; doxorubicin; nanoparticle; polymeric micelle; drug release; pharmacokinetics; pH; dorsal skin-fold window chamber model

Acta Pharmacologica Sinica (2014) 35: 839-845; doi: 10.1038/aps.2014.12

\section{Introduction}

Triggered drug release in the tumor interstitium after drugloaded nanovesicle release from tumor blood vessels may result in a high local concentration and lesser drug distribution to normal tissues. This has been one of the major goals in drug carrier design in chemotherapy ${ }^{[1-3]}$. The difference in $\mathrm{pH}$ between the solid tumors and normal tissues has been longrecognized among oncologists ${ }^{[4-7]}$. For example, the average extracellular $\mathrm{pH}$ of human solid tumors xenografted in mice

\footnotetext{
\#These authors contributed equally to this study.

* To whom correspondence should be addressed.

E-mail zggao@imm.ac.cn

Received 2013-10-12 Accepted 2014-01-13
}

falls below a $\mathrm{pH}$ of $7.0^{[8]}$, while the $\mathrm{pH}$ value of normal tissue is approximately 7.4. The difference is small but apparent and could be used as a pathophysiological stimulus for triggering drug release. Some approaches have demonstrated that carriers with $\mathrm{pH}$-sensitive chemical bonds could induce accelerated drug release at a lower endosomal $\mathrm{pH}^{[9]}$. This approach, however, is not currently applicable to effectively target the tumor extracellular $\mathrm{pH}$ effectively. Core-destabilizing polymeric micelles have been produced that might take advantage of tumor acidity ${ }^{[10-16]}$. Micelles $94 \mathrm{~nm}$ in size were constructed with poly(L-histidine) ( $5000 \mathrm{Da})$ - $b$-poly(ethylene glycol) $(\sim 5000 \mathrm{Da})$ (polyHis-b-PEG). L-histidine is a major basic amino acid responsible for the buffering capacity of biological systems, and its base form has a $\mathrm{p} K_{\mathrm{b}}$ of $6.5^{[2]}$. PolyHis 
block forms the micellar core when the $\mathrm{pH}$ is above 7.4, but the core is destabilized by the ionization of His residues when the $\mathrm{pH}$ is below 7.0. The detailed synthesis of polyHis- $b$-PEG was described in our previous paper ${ }^{[3]}$. The characteristics of micelles including the $\mathrm{pH}$-dependent stability of such micelles at approximately the tumor extracellular $\mathrm{pH}$ were also reported $^{[2]}$. The result of anticancer drug delivery by such $\mathrm{pH}-$ sensitive micelles to solid tumors has demonstrated greatly improved antitumor efficacy and significantly reduced toxicity in an A2780 ovarian cancer animal model ${ }^{[15,17]}$. However, the mechanisms of the release of $\mathrm{pH}$-sensitive micelles from tumor blood vessels and the release of the drug in weakly acidic tumor interstitia have not yet been clarified in vivo. In this study, we established a visible extravasation animal model, a so-called dorsal skin-fold window chamber model, for the evaluation of $\mathrm{pH}$-sensitive micelle release from tumor blood vessels into interstitia.

\section{Materials and methods Materials}

L-Histidine, carbobenzoxy (CBZ), nystatin, insulin, penicillinstreptomycin, triethylamine (TEA) and dimethylsulfoxide (DMSO) were purchased from Sigma-Aldrich Chemical Corp. Doxorubicin $\cdot \mathrm{HCl}$ was purchased from Beijing Huafeng United Technology Co, Ltd. Trypsin, fetal bovine serum and RPMI1640 media were provided by Hyclone. Other chemicals were of an analytical grade.

\section{Cell lines and animals}

MDA-MB-231 breast cancer cells were provided by the Department of Pathology, Institute of Medicinal Biotechnology in Peking Union Medical College. The cells were cultured in $75-\mathrm{cm}^{2}$ cell culture flasks using RPMI-1640 media supplemented with $10 \%$ fetal bovine serum, $0.4 \%$ nystatin, $1.2 \%$ insulin and $1.2 \%$ penicillin-streptomycin. The media were changed every other day. The incubators were maintained at $5.0 \% \mathrm{CO}_{2}$ and $36.5^{\circ} \mathrm{C}$. Cells in the logarithmic growth phase were used to conduct all the cell experiments in this study. Male Sprague-Dawley rats (Beijing Vital River Laboratories) were used for pharmacokinetics tests; female 6-week-old nude mice (Beijing Vital River Laboratories) were used for in vivo flow cytometry, dorsal skin-fold window chamber models and tumor growth inhibition tests. The animals were housed and maintained in the animal facility of the Animal Center of the Chinese Academy of Medical Sciences. The animal protocol was reviewed and approved by the Institutional Animal Care and Use Committee of the Chinese Academy of Medical Sciences and the Animal Ethics Committee of the institute.

\section{Synthesis of PolyHis-b-PEG}

Poly(L-His)- $b$-PEG was synthesized as described before ${ }^{[2]}$. Briefly, after L-histidine (His) was derivatized by introducing a carbobenzoxy (CBZ) group onto the amino group, the amino group in the imidazole ring of $N$-CBZ-L-histidine was protected with a dinitrophenyl (DNP) group. N-CBZ-N-DNP$L$-histidine was then transformed to the $N$-carboxyanhydride
(NCA) form by thionyl chloride. The ring-opening polymerization of NCA was initiated with isopropylamine. The purified poly(N-DNP-His) was coupled with carboxylated PEG to yield diblock copolymers. The polymer was then deprotected by thiolysis with 2-mercaptoethanol by our routine method ${ }^{[6]}$.

\section{DOX-loaded pH-sensitive micelles}

The DOX-loaded polyHis/PEG micellar formulation was prepared as described previously ${ }^{[2,3]}$. Briefly, Doxorubicin $\cdot \mathrm{HCl}$ (DOX $\cdot \mathrm{HCl})$ was stirred with excess triethylamine (TEA) (2 times DOX $\cdot \mathrm{HCl}$ ) in DMSO overnight to obtain the DOX base. The block polymer (50 mg) was dissolved in $10 \mathrm{~mL}$ of DMSO, mixed with a DOX base solution (10 mg DOX base in $10 \mathrm{~mL}$ DMSO) and stirred for $3 \mathrm{~h}$. The solution was transferred to a pre-swollen dialysis membrane (Spectra/Por with molecular weight cutoff 15000) and dialyzed against $\mathrm{NaOH}-\mathrm{Na}_{2} \mathrm{~B}_{4} \mathrm{O}_{7}$ buffer solution ( $\mathrm{pH} 9.0$ ) for $24 \mathrm{~h}$ at $4{ }^{\circ} \mathrm{C}$. The medium was exchanged several times, and the contents of the dialysis tube were subsequently lyophilized.

\section{Determination of encapsulation efficiency and DOX-loading capacity}

The concentration of entrapped DOX was determined by HPLC after being dissolved in 10\% DMSO in methanol ${ }^{[17]}$. The process was assayed on an Agilent 1200LC (Agilent Tech, USA) HPLC system. A Cosmosil ODS $\mathrm{C}_{18}$ column (5 $\mu \mathrm{m}, 4.6 \mathrm{~mm} \times 150 \mathrm{~mm}$ ) was used. The mobile phase consisted of a buffer $(1.44 \mathrm{~g}$ of sodium dodecylsulfate and $0.68 \mathrm{~mL}$ of phosphoric acid dissolved in $500 \mathrm{~mL}$ of water)-acetonitrilemethanol (500:500:60, v:v:v) delivered at a flow rate of $1.0 \mathrm{~mL} /$ min. The injection volume was $20 \mu \mathrm{L}$, and the wavelength was set at $254 \mathrm{~nm}$. The column temperature was $25^{\circ} \mathrm{C}$. The concentration of DOX was determined based on the peak area.

The $\mathrm{pH}$-sensitive micelles were destroyed by adding a $3 \times$ volume of methanol, and the total content of DOX was determined by using HPLC. Then, the solution was centrifuged through a $30000 \mathrm{kDa} \mathrm{MWCO}$ filter (Millipore) at $4{ }^{\circ} \mathrm{C}$. The content of DOX in the lower chamber of the filter device was also determined. The loading capacity of DOX was determined by HPLC after dissolving with acetonitrile (1:10, $w / v)$. DOX Loading Capacity $(w / w \%)=$ amount of physically loaded DOX/amount of DOX-micelles $\times 100 \%$; Encapsulation Efficiency=amount of physically loaded DOX/amount of DOX initially added $\times 100 \%$.

\section{CMC measurement}

For measurement of critical micelle concentration (CMC) of the diblock copolymer, $6.0 \times 10^{-7} \mathrm{~mol} / \mathrm{L}$ of final pyrene concentration was added in each sample. The fluorescent intensity of each sample emission at $339 \mathrm{~nm}$ was measured. The CMC of each sample was calculated by plotting the emission spectrum profile against the logarithm of the diblock copolymer's concentration.

\section{In vitro and in vivo flow cytometry}

MDA-MB-231 breast cancer cells $\left(1 \times 10^{6}\right.$ cells/well) were 
seeded in a 6-well plate and incubated overnight and harvested by $0.2 \%(w / v)$ trypsin- $0.1 \%(w / v)$ EDTA solution. Two milliliters of free DOX and DOX-loaded micelles, with 25 $\mu \mathrm{g} / \mathrm{mL}$ DOX in the medium, was introduced to each well and incubated for $25 \mathrm{~min}$. The cells were trypsinized and washed three times with PBS solution and then fixed with $2.5 \%$ glutaraldehyde. After filtering through a nylon mesh, cell fluorescence was measured by flow cytometry (FACSCAN, Becton Dickinson) ${ }^{[18]}$. For the in vivo tumor cell uptake of DOXloaded micelles, DOX in various micelles was injected through the tail vein of mice. At $12 \mathrm{~h}$ after intravenous injection, the animals were sacrificed, and the tumors were excised and then dried on filter paper. After digestion by trypsin, the tumors were fixed with $2.5 \%$ glutaraldehyde, filtered through a nylon mesh, and measured by flow cytometry ${ }^{[17]}$.

\section{Dorsal skin-fold window chamber}

To implant titanium window chamber frames in the mice ${ }^{[5,19-21]}$, the animals were anesthetized ip with ketamine at a dose of $100 \mathrm{mg} / \mathrm{kg}$ of body weight. One side of the skin was peeled, making a flap on the left side that was approximately $1 \mathrm{~cm}$ in diameter; the skin and underlying fascia tissue on the right side remained intact. A pair of titanium windows was mounted in alignment with the circular wound, which was then covered with a glass cover slip and a retaining ring after an MDA-MB-231 tumor fragment (approximately 0.1 $\mathrm{mm}^{3}$ ) was implanted onto the fascia. Following recovery from anesthesia and surgery, the animals were housed in an environmental chamber at $35^{\circ} \mathrm{C}$ with $50 \%$ humidity and a 12 -h light/12-h dark cycle, with access to rodent chow and water ad libitum. These conditions were necessary to maintain the viability of the chamber and to provide a high enough temperature to facilitate tumor growth. The fluorescent light intensities of the entire selected region and representative vascular regions were measured at each serial time point. Microcirculatory parameters were analyzed by intravital fluorescence microscopy ${ }^{[22,23]}$ using an Olympus microscope (Olympus BX51WI Microscope, Leeds Precision Instruments, Inc, MN, USA) specially designed for animal experiments.

\section{Pharmacokinetics}

To examine the pharmacokinetics of DOX micelles in the mouse body, DOX in PBS solution, DOX pH-insensitive micelles and DOX in pH-sensitive micelles were injected iv through the sublingual vein in rats at DOX base dose of 10 $\mathrm{mg} / \mathrm{kg}$. At given time intervals (5, $30 \mathrm{~min}, 1,2,4,12$, and 24 h) post-injection, the rats were anesthetized by methoxyflurane. Blood was collected via cardiac puncture and placed in microtubes with $10 \mu \mathrm{L} 50 \mathrm{U} / \mathrm{mL}$ heparin. The whole blood $(0.8 \mathrm{~mL})$ was transferred to a tube, which contained $200 \mathrm{mg}$ of daunomycin as the internal standard and $0.01 \mathrm{~mol}$ silver nitrate to prevent DOX from binding to $\mathrm{DNA}^{[8]}$. Triple extractions were performed after adding chloroform/isopropyl alcohol $(3: 1, v / v)$. The solutions were frozen overnight, thawed, and centrifuged at $16000 \times g$ for $10 \mathrm{~min}$. The organic phase was removed, and the resulting solutions were evapo- rated to dryness and re-dissolved in a mobile phase solution (methanol/isopropyl alcohol/Sorensen's buffer, 2:2:6, v/v/v). These samples were analyzed (at excitation wavelength 480 $\mathrm{nm}$ and emission wavelength $560 \mathrm{~nm}$ ) using an HPLC system. HPLC of DOX was performed using a Supelco LC-18 column (250 $\mathrm{mm} \times 4.6 \mathrm{~mm}$ id, $5 \mathrm{~mm}$ particle size) and a Hitachi HPLC instrument (D-6000 interface, F-1080 Fluorescence Detector; L-6200A intelligent pump, and AS-2000 Autosampler). The non-compartmental pharmacokinetic parameters, which included the area under the drug concentration time curve (AUC), $t_{1 / 2}$, clearance (CL), volume of distribution of drug $\left(V_{\mathrm{d}}\right)$ and mean retention time (MRT), were calculated using the trapezoidal rule. The data between the different formulations were compared for statistical significance by a one-way analysis of variance (ANOVA).

\section{Tumor growth inhibition}

The xenografts of human breast MDA-MB-231 carcinoma cells were developed after implanting $2 \mathrm{~mm} \times 2 \mathrm{~mm}$ tumor pieces into a window chamber. When the tumor volume reached approximately $50 \mathrm{~mm}^{3}$, all of the animals were treated thrice at 3-d intervals with either DOX-loaded $\mathrm{pH}$-sensitive micelles or $\mathrm{pH}$-insensitive micelles. The mice were safely treated without losing much weight during the treatment. Both the micelle formulations and free drugs were injected intravenously via tail vein at the DOX base dose of $10 \mathrm{mg} / \mathrm{kg}$ through $25 \mathrm{G}^{5 / 8}$ needles. The tumor inhibition activity was assessed with the tumor volume size, which was calculated by the following equation: $V=(w)^{2} \times(l) / 2$, where $(w)$ and $(l)$ are width and length of the tumor measured by a caliper with a 3-d interval.

\section{Results}

\section{The characterization of DTX-PM}

The encapsulation efficiency and loading capacity were 98\% and $13 \%$, respectively, for the $\mathrm{pH}$-sensitive micelles and $99 \%$ and $23 \%$, respectively, for the $\mathrm{pH}$-insensitive micelles. The $\mathrm{CMC}$ values of the $\mathrm{pH}$-sensitive micelles were 201 (at $\mathrm{pH} 5$ ), 145 ( $\mathrm{pH}$ 6), 72 ( $\mathrm{pH} 6.8), 31$ (pH 7.0), 5.6 (pH 7.4), and $1.2(\mathrm{pH}$ $8.0) \times 10^{-3} \mathrm{mg} / \mathrm{mL}$, respectively. These results indicated that increasing the $\mathrm{pH}$ level resulted in decreased $\mathrm{CMC}$ values.

\section{Cell uptake at different $\mathrm{pH}$ values}

Here, we report on the visualization of $\mathrm{pH}$-sensitive micelles from the blood vessels developed in MDA-MB-231 breast tumors and Doxorubicin accumulation in tumors of the mouse dorsal skin-fold window chamber model. Prior to the in vivo study, MDA-MB-231 breast cancer cells were incubated in $\mathrm{pH} 7.4$ and $\mathrm{pH} 6.8$ media at a base micelle concentration of 25 $\mu \mathrm{g} / \mathrm{mL}$ DOX for an initial time period of $25 \mathrm{~min}$. The resulting fluorescence histograms of the cellular uptake of DOX are presented in Figure 1A. All of the cell population profiles were unimodal, and the profiles were shifted to higher fluorescence intensity regions when the cells were treated with DOX-loaded polyHis- $b$-PEG micelles at two different pHs (normal blood $\mathrm{pH}$ and the tumor extracellular $\mathrm{pH}$ ). The DOX fluorescence intensity of the cells treated at $\mathrm{pH} 6.8$ appeared approximately 


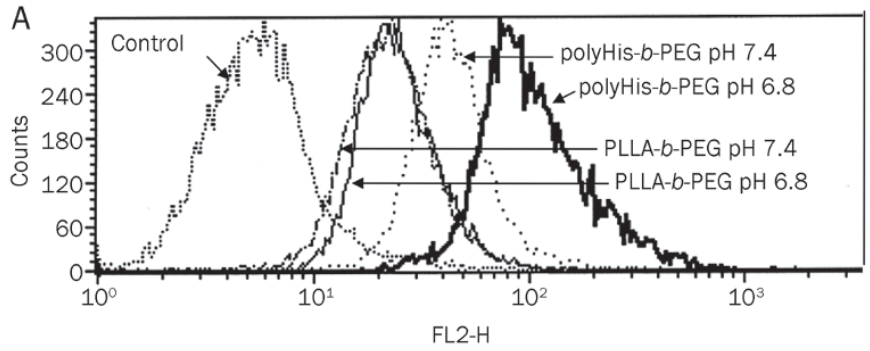

B

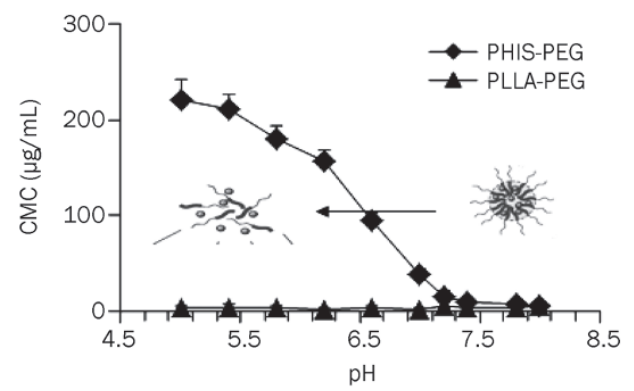

Figure 1. Fluorescence histograms of breast cancer MDA-231 cells incubated with DOX loaded into polyHis-b-PEG pH-sensitive micelles. DOX $(25 \mu \mathrm{g})$ was incorporated into $125 \mu \mathrm{g}$ polyHis-b-PEG micelles per $\mathrm{mL}$ solution. Cells were incubated in $\mathrm{pH} 6.8$ medium, $\mathrm{pH} 7.4$ medium and control plain medium without DOX. All cells were incubated for 25 min after adding the formulations (A). The CMC of polyHis-b-PEG micelles as a function of $\mathrm{pH}$ value was present $(\mathrm{B})$. $\mathrm{pH}$ sensitive micelles (particle size approximately $95 \mathrm{~nm}$, measured by dynamic light scattering) were dissociated at a $\mathrm{pH}$ lower than 7.0 in the media ( $\mathbf{m})$, whereas the $\mathrm{pH}$ insensitive micelles remained intact as the $\mathrm{pH}$ was reduced to $4.5(\mathbf{A})$.

5 times higher than at $\mathrm{pH} 7.4$, confirming a higher DOX availability to the tumor cells incubated at $\mathrm{pH} 6.8$ from the beginning of the treatment with $\mathrm{pH}$-sensitive micelles. This may be one of a variety of reasons why the inclusion of a sparingly water-soluble drug may overcome cancer cell multi-drug resistance and promote drug absorption by poly-histidine.

However, the DOX fluorescence intensity of the cells at $\mathrm{pH}$ 7.4 and 6.8 was similar when a control sample of $\mathrm{pH}$-insensitive micelles prepared from poly (L-lactic acid)-b-PEG (PLLA$b$-PEG) was used. The $\mathrm{pH}$-sensitive micelles were destabilized at a lower $\mathrm{pH}$, resulting in an accelerated DOX release $\mathrm{e}^{[4]}$. This was consistent with the $\mathrm{pH}$-dependent critical micelle concentration $(\mathrm{CMC})$, which increased as the $\mathrm{pH}$ value decreased (Figure 1B).

\section{Pharmacokinetic parameters}

The blood concentration-time profiles of DOX after iv administration of free DOX dissolved in PBS, DOX in $\mathrm{pH}$-insensitive micelles and DOX loaded into $\mathrm{pH}$-sensitive micelles are shown in Figure 2. Each formulation was administered to rats (female, $n=5$ ) at a DOX dose of $6 \mathrm{mg} / \mathrm{kg}$. The DOX concentration of DOX was approximately $1.5 \mu \mathrm{g} / \mathrm{mL}, 1.1 \mu \mathrm{g} / \mathrm{mL}$ and $0.21 \mu \mathrm{g} / \mathrm{mL}$, respectively, after the administration of $\mathrm{pH}$-sensitive, insensitive and DOX PBS at $4 \mathrm{~h}$, and above $0.1 \mu \mathrm{g} / \mathrm{mL}$ of the blood DOX level, even at $24 \mathrm{~h}$ after the administration of

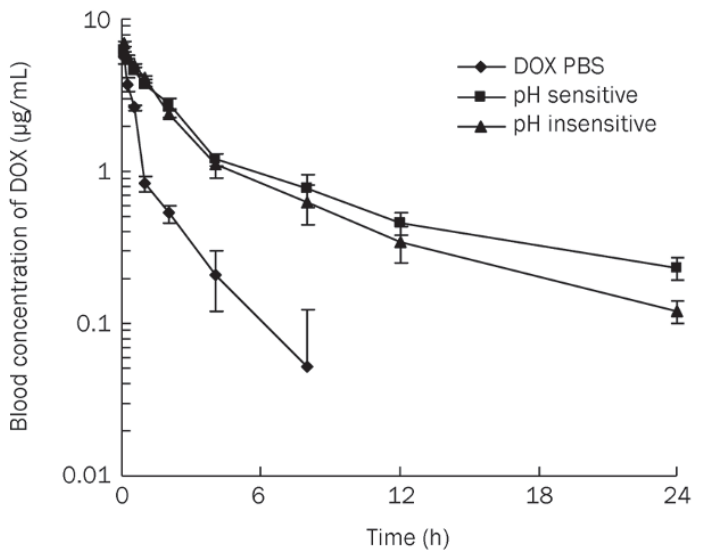

Figure 2. The blood concentration-time profiles of DOX after iv administration of DOX PBS, DOX loaded into $\mathrm{pH}$-sensitive micelles and DOX loaded into $\mathrm{pH}$-insensitive micelles. Each formulation was administered to mice (female, $n=5$ ) at a DOX dose of $6 \mathrm{mg} / \mathrm{kg}$.

DOX in micelles. The free DOX concentration was not detectable in our measurement condition (detection limit: $50 \mathrm{ng} / \mathrm{mL}$ ) after $8 \mathrm{~h}$. The non-compartmental pharmacokinetic parameters were calculated using the trapezoidal rule. The effective elimination half-life $t_{1 / 2}$ of the $\mathrm{pH}$-sensitive micelle formulation was 5 times longer than the DOX PBS solution (11.3 vs $2.1 \mathrm{~h}$ ) and 1.2 times longer than the $\mathrm{pH}$-insensitive micelles (11.3 vs $9.4 \mathrm{~h}$ ), while the total CL decreased (1923 vs 367 $\left.\mathrm{mL} \cdot \mathrm{min}^{-1} \cdot \mathrm{kg}^{-1}\right)$. The PEG graft on the surface of the micelles seemed to be responsible for the increased circulation time in the blood. In addition, the mean residence time (MRT) (2.6 vs $13.5 \mathrm{~h}$ ) and VD at steady state (Vdss) (4024 vs $3987 \mathrm{~L} / \mathrm{kg}$ ) were calculated for the DOX-loaded $\mathrm{pH}$-sensitive micelles and free DOX dissolved in PBS solution.

\section{Drug release from tumor blood vessel}

A $2 \mathrm{~mm} \times 2 \mathrm{~mm}$ tumor implanted into a BALB/c mouse window chamber is shown in Figure 3A. Blood vessel developments in the window chamber on $\mathrm{d} 1$ and 15 after tumor implantation are shown in Figure 3B and Figure 3C, respectively. The fluorescence was confined to the vessels in physiology granulation tissue, as observed after intravenous injection of DOX-loaded $\mathrm{pH}$-sensitive micelles through the mouse tail vein. The release of micelles from normal blood vessels was very limited at two initial time points ( $5 \mathrm{~min}$ to $60 \mathrm{~min}$ ) as shown in Figure 3D and 3E.

The endothelial cells of the blood vessels in normal tissue were joined by tight junctions that prevented penetration of nanoparticles, as shown in Figures 3D and 3E. In contrast, the tumors were characterized by a defective vasculature with large gaps between the endothelial cells that allowed the nanoparticles to enter into gaps up to $750 \mathrm{~nm}$ in size ${ }^{[5,24]}$. This permeability allows for accumulation of drug-loaded micelles in the tumor interstitium via the enhanced permeability and retention (EPR) effect ${ }^{[25-27]}$. The diffusion rate of DOX from tumor blood vessels for the $\mathrm{pH}$-sensitive micelles was greater 

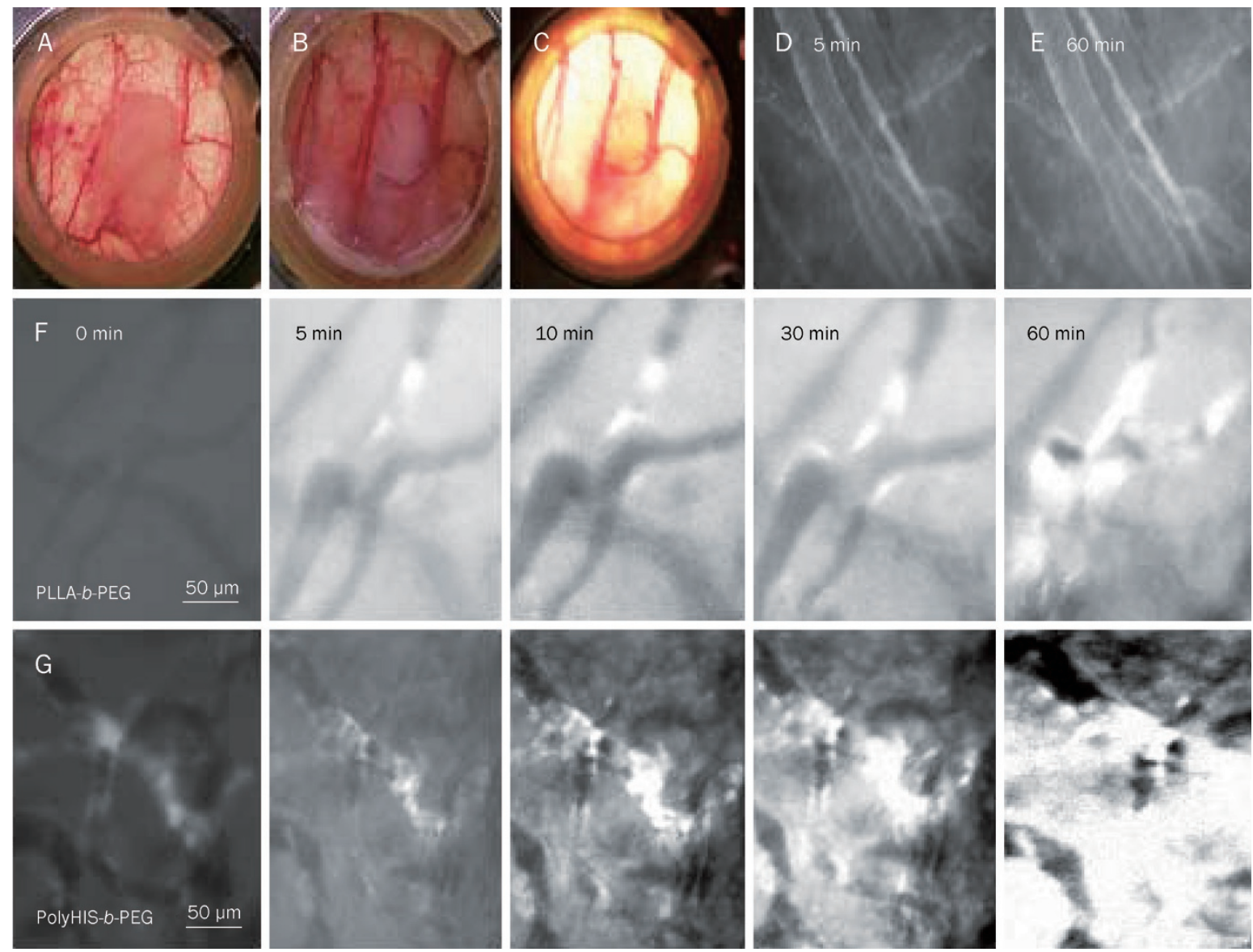

Figure 3. Mouse dorsal skin-fold window chamber made of two symmetrical titanium frames. A tumor xenograft was inoculated into a nu/nu mouse window chamber (A). After implanting the MDA-231 breast cancer tumor xenograft, tumor blood vessels were observed to be growing in the window chamber on $\mathrm{d} 1$ (B) and d 15 (C). Normal blood vessel images after iv injection of DOX-loaded pH-sensitive micelles 5 min and 60 min are shown in (D) and $(\mathrm{E})$, respectively. The tumor blood vessels after iv injection of DOX-loaded $\mathrm{pH}$-insensitive and $\mathrm{pH}$-sensitive micelles at the time course for 60 min are presented in $(\mathrm{F})$ and $(\mathrm{G})$ rows. The tight junctions between cells in the endothelial lining of blood vessels in normal tissues do not allow the drugloaded micelles (indicated by cross) to enter into the tissues. In contrast, tumors are characterized by defective vasculature with large gaps between the endothelial cells, which allowed the drug-loaded micelles enter into the gaps, causing their accumulation in the tumor interstitium.

than the $\mathrm{pH}$-insensitive micelles (Figure 3), suggesting that the rapid dissociation of $\mathrm{pH}$-sensitive micelles in low-pH tumor tissue may reduce the barrier in tumor blood vessels.

\section{Tumor growth inhibition}

The serial images of DOX-loaded $\mathrm{pH}$-sensitive and $\mathrm{pH}$-insensitive micelles from tumor blood vessels are shown in two rows of Figures 3F and 3G. MDA-MB-231 cells xenografted in the nude mouse dorsal skin-fold window chamber model were used to study tumor growth inhibition in vivo. The antitumor activity of the DOX-loaded $\mathrm{pH}$-sensitive micelles injected intravenously on d 0,3, and 6 is shown in Figure 4A. After $21 \mathrm{~d}$, the DOX-loaded $\mathrm{pH}$-sensitive micelles significantly inhibited the growth of MDA-MB-231 xenografts in nude mice (5 mice per group) when compared with the DOX-loaded $\mathrm{pH}$ insensitive micelles and control group $(P<0.01, P<0.01$ compared with control and $\mathrm{pH}$-insensitive micelles; ANOVA test). After $21 \mathrm{~d}$ of treatment, the tumor volumes of the control and $\mathrm{pH}$-insensitive micelle-treated groups were approximately
6.8- and 4.3-fold larger than the group treated with the $\mathrm{pH}-$ sensitive micelles. To further clarify drug concentrations in cancer cells in vivo, the cells were extracted from tumor tissues $12 \mathrm{~h}$ post-administration of $10 \mathrm{mg} / \mathrm{kg}$ of DOX and examined by flow cytometry. A high fluorescence intensity with a unimodal distribution of the cell population was observed when treated with $\mathrm{pH}$-sensitive micelles. However, there was a bimodal distribution of cells with varying fluorescence intensity in the group treated with the $\mathrm{pH}$-insensitive micelles. Approximately $14 \%$ of the total tumor cells appeared to show high DOX uptake. The intensity of cellular uptake of DOX supplied from the $\mathrm{pH}$-sensitive micelles was approximately 3.3-fold higher than the $\mathrm{pH}$-insensitive micelles, as shown in Figure 4B. Tumor cells with a unimodal distribution of high DOX fluorescence intensity in the cell population correlated with slowly growing tumors.

The $\mathrm{pH}$-sensitive micelles prepared with polyHis-b-PEG showed preferential drug accumulation in the tumor site, most likely by the combined effects of a longer circulation time 

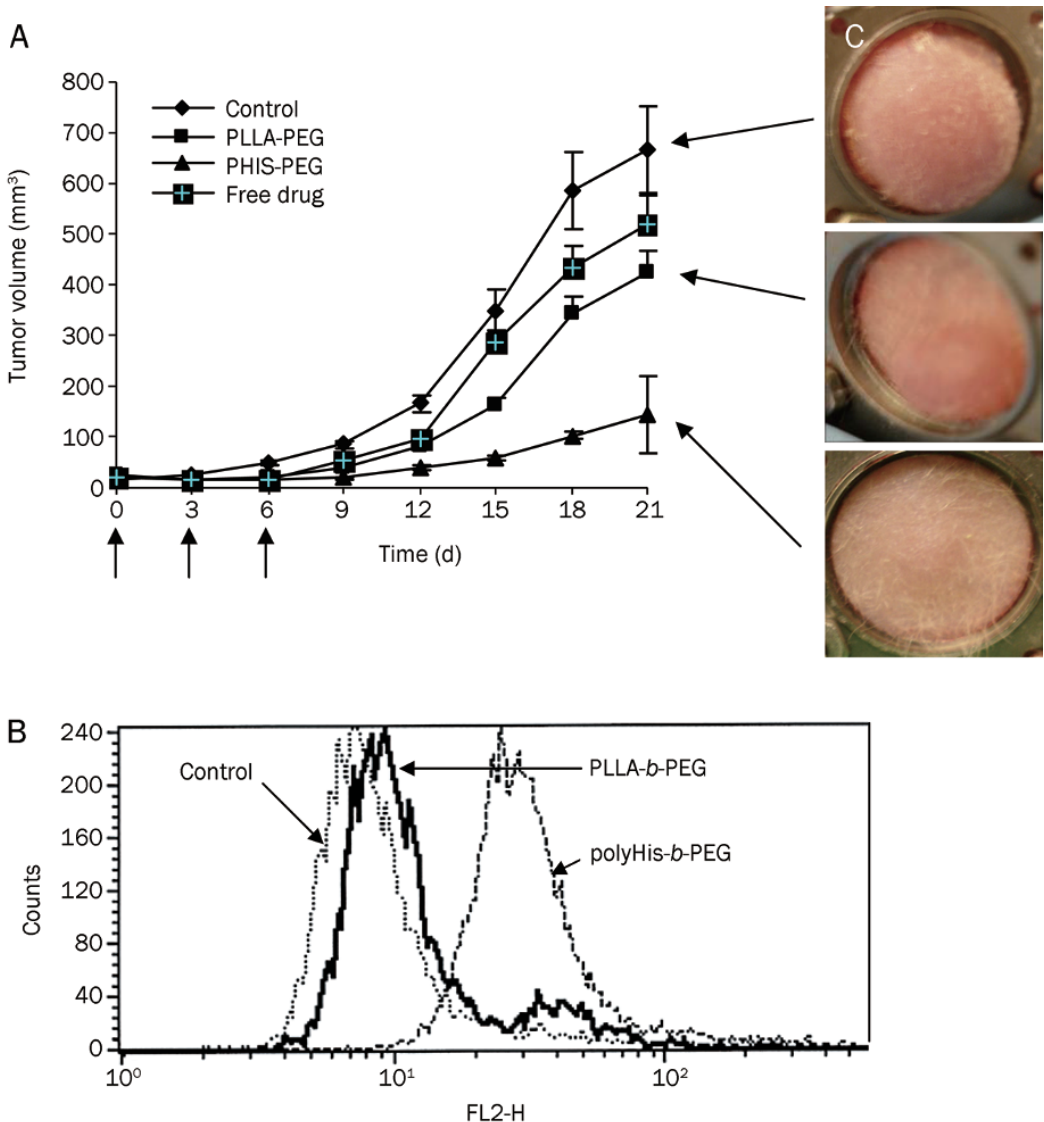

Figure 4. Effects of DOX-loaded pHsensitive micelles and $\mathrm{pH}$-insensitive micelles on the growth of MDA 231 breast carcinoma in the window chamber model are presented in (A) and DOX uptake by MDA-231 breast tumor cells in vivo was evaluated by flow cytometry (B). Each formulation was administered three times at 3-day intervals (arrows) at a dose of 10 $\mathrm{mg} / \mathrm{kg}$ for tumor growth inhibition study. For the in vivo tumor cell uptake test, tumor cells were extracted and evaluated by flow cytometry after a 12-h administration of DOX-loaded $\mathrm{pH}$-sensitive micelles at a dose of $10 \mathrm{mg} / \mathrm{kg}$. in the bloodstream ${ }^{[17]}$, micellar disintegration and triggered drug release in the relatively acidic tumor interstitium. This enhanced the bioavailability of DOX in the tumor cells, resulting in improved antitumor efficacy. The drug accumulation processes were successfully observed using the dorsal window chamber model.

\section{Discussion}

As described in this study, the chemotherapy drug, DOX, when loaded into $\mathrm{pH}$-sensitive micelles and released from tumor blood vessels, as shown in the dorsal window chamber model, effectively inhibited tumor volume growth in breast cancer cell tumor-bearing mice. The core of the micelle was composed of $\mathrm{pH}$-sensitive poly-histidine dissociates under the lower $\mathrm{pH}$ caused by deprotonation. The hydrophobic drug contained in the micelle core was released upon micelle dissociation, leading to enhanced drug uptake by cancer cells, as shown in Figure 1. In contrast, the release of the drug in the $\mathrm{pH}$-insensitive micelle composed of PLLA-PEG was much reduced compared to the $\mathrm{pH}$-sensitive micelle because the strong hydrophobic core architecture still existed in the micelle, as we previously described ${ }^{[3]}$. The CMC was increased with a reduction of the $\mathrm{pH}$ in the medium because of the prompt deprotonation of the lone electronic pairs on the nitrogen of the imidazole ring in the poly-histidine structure, while the $\mathrm{pH}$-insensitive micelle still maintained a low CMC under various $\mathrm{pH}$ conditions. It was demonstrated that the
pH-sensitive poly-histidine micelle could be stable at a normal of pH 7.4 and could disintegrate at a low $\mathrm{pH}$, which is very useful for acidic solid tumor targets.

DOX itself emits red fluorescence, and its excitation and emission wavelengths are $488 \mathrm{~nm}$ and $510 \mathrm{~nm}$, respectively. The release of DOX from tumor blood vessels can be visualized in the window chamber by an intravital fluorescent microscope. A $2 \mathrm{~mm} \times 2 \mathrm{~mm}$ tumor implanted into a BALB/c mouse via the window chamber model is shown in Figure $3 \mathrm{~A}$. The endothelial cells of the blood vessels in normal tissue were joined by tight junctions that prevented penetration of nanoparticles, as shown in Figure 3D and 3E. In contrast, the tumors were characterized by a defective vasculature with large gaps between the endothelial cells, which allowed the nanoparticles to enter into gaps up to $750 \mathrm{~nm}$ in size ${ }^{[5,24]}$. This permeability allowed for the accumulation of drug-loaded micelles in the tumor interstitium via the enhanced permeability and retention (EPR) effect ${ }^{[25-27]}$. The diffusion rate of DOX from tumor blood vessels in $\mathrm{pH}$-sensitive micelles was greater than in $\mathrm{pH}$-insensitive micelles (Figure 3), suggesting that the rapid dissociation of $\mathrm{pH}$-sensitive micelles in low-pH tumor tissues may reduce the barrier in tumor blood vessels.

The $\mathrm{pH}$-sensitive micelles prepared with polyHis- $b$-PEG showed preferential drug accumulation in the tumor site, most likely by the combined effects of a longer circulation time in the bloodstream ${ }^{[17]}$, micellar disintegration and triggered drug release in the relatively acidic tumor interstitium. 
This enhanced the bioavailability of DOX into the tumor cells, resulting in improved antitumor efficacy. The drug accumulation processes were successfully observed by the dorsal window chamber model.

In conclusion, we successfully established a visible extravasation animal model, the so-called dorsal skin-fold window chamber model, for the evaluation and clarification of the mechanisms of drug delivery released from tumor blood vessels into interstitia. The cores of $\mathrm{pH}$ non-sensitive PEGPLLA and $\mathrm{pH}$-sensitive micelles were composed of poly(Lhistidine)- $b$-poly(ethylene glycol) and were prepared for comparing drug release patterns in the acidic environment of solid tumors. Intravital microscope evaluation showed that the $\mathrm{pH}$ sensitive micelle was preferentially released at the tumor site when compared to the $\mathrm{pH}$-insensitive micelle system. The destabilization of the $\mathrm{pH}$-sensitive micelles and the triggered drug release caused by the tumor acidity were the major mechanisms resulting in high local concentrations of DOX in the tumor. The $\mathrm{pH}$-sensitive micelles significantly inhibited tumor growth in vivo when chemotherapy drugs were loaded into the hydrophobic core.

\section{Acknowledgements}

This research was supported by the National Natural Science Foundation of China (No 81373342), and the Natural Science Foundation of Beijing (№ 2141004 and 7142114).

\section{References}

1 Kataoka K, Matsumoto T, Yokoyama M, Okano T, Sakurai Y, Fukushima $\mathrm{S}$, et al. Doxorubicin-loaded poly(ethylene glycol)-poly(beta-benzyl-Laspartate) copolymer micelles: Their pharmaceutical characteristics and biological significance. J Control Release 2000; 64: 143-53.

2 Lee ES, Na K, Bae YH. Polymeric micelle for tumor $\mathrm{pH}$ and folatemediated targeting. J Control Release 2003; 91: 103-13.

3 Lee ES, Shin HJ, Na K, Bae YH. Poly(L-histidine)-peg block copolymer micelles and pH-induced destabilization. J Control Release 2003; 90: 363-74.

4 Tannock IF, Rotin D. Acid pH in tumors and its potential for therapeutic exploitation. Cancer Res 1989; 49: 4373-84.

5 Hobbs SK, Monsky WL, Yuan F, Roberts WG, Griffith L, Torchilin VP, et al. Regulation of transport pathways in tumor vessels: Role of tumor type and microenvironment. Proc Natl Acad Sci U S A 1998; 95 : 4607-12.

6 Stubbs M, McSheehy PM, Griffiths JR, Bashford CL. Causes and consequences of tumour acidity and implications for treatment. Mol Med Today 2000; 6: 15-9.

7 Engin K, Leeper DB, Cater JR, Thistlethwaite AJ, Tupchong L, McFarlane JD. Extracellular pH distribution in human tumours. Int $\mathrm{J}$ Hyperthermia 1995; 11: 211-6.

8 Gao ZG, Fain HD, Rapoport N. Controlled and targeted tumor chemotherapy by micellar-encapsulated drug and ultrasound. J Control Release 2005; 102: 203-22.

9 Park TG. Perfusion culture of hepatocytes within galactose-derivatized biodegradable poly(lactide-co-glycolide) scaffolds prepared by gas foaming of effervescent salts. J Biomed Mater Res 2002; 59: 127 35.
$10 \mathrm{Na} \mathrm{K}$, Bae YH. Self-assembled hydrogel nanoparticles responsive to tumor extracellular $\mathrm{pH}$ from pullulan derivative/sulfonamide conjugate: Characterization, aggregation, and adriamycin release in vitro. Pharm Res 2002; 19: 681-8.

$11 \mathrm{Na} \mathrm{K}$, Lee ES, Bae YH. Adriamycin loaded pullulan acetate/ sulfonamide conjugate nanoparticles responding to tumor $\mathrm{pH}$ : $\mathrm{pH}$ dependent cell interaction, internalization and cytotoxicity in vitro. J Control Release 2003; 87: 3-13.

12 Sethuraman VA, Na K, Bae YH. Ph-responsive sulfonamide/pei system for tumor specific gene delivery: An in vitro study. Biomacromolecules 2006; 7: 64-70.

$13 \mathrm{Kang} \mathrm{SI}$, Bae $\mathrm{YH}$. pH-induced solubility transition of sulfonamidebased polymers. J Control Release 2002; 80: 145-55.

$14 \mathrm{Kang} \mathrm{SI}$, Bae $\mathrm{YH}$. pH-dependent elution profiles of selected proteins in HPLC having a stationary phase modified with $\mathrm{pH}$-sensitive sulfonamide polymers. J Biomater Sci Polym Ed 2004; 15: 879-94.

15 Lee ES, Na K, Bae YH. Doxorubicin loaded pH-sensitive polymeric micelles for reversal of resistant MCF-7 tumor. J Control Release 2005; 103: 405-18.

16 Lee ES, Na K, Bae YH. Super pH-sensitive multifunctional polymeric micelle. Nano Lett 2005; 5: 325-9.

17 Gao ZG, Lee DH, Kim DI, Bae YH. Doxorubicin loaded pH-sensitive micelle targeting acidic extracellular $\mathrm{pH}$ of human ovarian a2780 tumor in mice. J Drug Target 2005; 13: 391-7.

18 Gao Z, Fain HD, Rapoport N. Ultrasound-enhanced tumor targeting of polymeric micellar drug carriers. Mol Pharm 2004; 1: 317-30.

19 Monsky WL, Fukumura D, Gohongi T, Ancukiewcz M, Weich HA, Torchilin VP, et al. Augmentation of transvascular transport of macromolecules and nanoparticles in tumors using vascular endothelial growth factor. Cancer Res 1999; 59: 4129-35.

20 Wu NZ, Braun RD, Gaber MH, Lin GM, Ong ET, Shan S, et al. Simultaneous measurement of liposome extravasation and content release in tumors. Microcirculation 1997; 4: 83-101.

21 Lichtenbeld HC, Yuan F, Michel CC, Jain RK. Perfusion of single tumor microvessels: Application to vascular permeability measurement. Microcirculation 1996; 3: 349-57.

22 Tozer GM, Prise VE, Wilson J, Cemazar M, Shan S, Dewhirst MW, et al. Mechanisms associated with tumor vascular shut-down induced by combretastatin a-4 phosphate: Intravital microscopy and measurement of vascular permeability. Cancer Res 2001; 61: 641322.

23 Dewhirst MW, Shan S, Cao Y, Moeller B, Yuan F, Li CY. Intravital fluorescence facilitates measurement of multiple physiologic functions and gene expression in tumors of live animals. Dis Markers 2002; 18: 293-311.

24 Campbell RB. Tumor physiology and delivery of nanopharmaceuticals. Anticancer Agents Med Chem 2006; 6: 503-12.

25 Bartlett DW, Su H, Hildebrandt IJ, Weber WA, Davis ME. Impact of tumor-specific targeting on the biodistribution and efficacy of sirna nanoparticles measured by multimodality in vivo imaging. Proc Natl Acad Sci U S A 2007; 104: 15549-54.

26 Shan S, Flowers C, Peltz CD, Sweet H, Maurer N, Kwon EJ, et al. Preferential extravasation and accumulation of liposomal vincristine in tumor comparing to normal tissue enhances antitumor activity. Cancer Chemother Pharmacol 2006; 58: 245-55.

27 GaozG, Lukyanov AN, Singhal A, Torchilin VP. Diacyllipid-polymer micelles as nanocarriers for poorly soluble anticancer drugs. Nano Lett 2002; 2: 979-82. 